\title{
Active Sites, Deactivation and Stabilization of Fe-ZSM-5 for the Selective Catalytic Reduction (SCR) of NO with $\mathrm{NH}_{3}$
}

\author{
Oliver Kröcher* and Sandro Brandenberger
}

\begin{abstract}
Fe-ZSM-5 has been systematically investigated as catalyst for the selective catalytic reduction (SCR) of $\mathrm{NO}$ with $\mathrm{NH}_{3}$, concentrating on the active sites, the deactivation mechanism during hydrothermal aging and the chemical possibilities to stabilize this type of SCR catalyst. Regarding the active SCR sites, it could be shown that monomeric species start to become active at the lowest temperatures $\left(E_{a, a p p} \approx 36.3 \pm 0.2 \mathrm{~kJ} / \mathrm{mol}\right)$, followed by dimeric species at intermediate temperatures $\left(\mathrm{E}_{\mathrm{a}, \mathrm{app}} \approx 77 \pm 16 \mathrm{~kJ} / \mathrm{mol}\right)$ and oligomeric species at high temperatures. Experiments with Fe-ZSM-5 samples, in which the Brønsted acidity was specifically removed, proved that Brønsted acidity is not required for high SCR activity and that $\mathrm{NH}_{3}$ can also be adsorbed on other acidic sites on the zeolite surface. The hydrothermal deactivation of Fe-ZSM-5 could be explained by the migration of active iron ions from the exchange sites. Parallel to the iron migration dealumination of the zeolite framework occurs, which has to be regarded as an independent process. The migration of iron can be reduced by the targeted reaction of the aluminum hydroxide groups in the lattice with trimethylaluminium followed by calcination. With respect to the application of iron zeolites in the SCR process in diesel vehicles, the most efficient stabilization method would be to switch from the ZSM- 5 to the BEA structure type. The addition of $\mathrm{NO}_{2}$ to the feed gas is another effective measure to increase the activity of even strongly deactivated iron zeolites tremendously.
\end{abstract}

Keywords: Active sites · Deactivation · Fe-ZSM-5 · SCR · Selective catalytic reduction · Stabilization

\section{Introduction}

Selective catalytic reduction $(\mathrm{SCR})$ with $\mathrm{NH}_{3}$ is today one of the most important $\mathrm{NO}_{\mathrm{x}}$ reduction technologies. Originally, $\mathrm{NH}_{3}^{\mathrm{x}}$-SCR was developed in Japan in the early 70 s for the removal of nitrogen oxides from the exhaust gas of stationary power stations ${ }^{[1]}$ and was later transferred to mobile applications. ${ }^{[2-4]}$ In order to avoid the transport of $\mathrm{NH}_{3}$ in mobile applications, urea solution was suggested as reducing agent, which hydrolyzes under hydrothermal conditions to $\mathrm{NH}_{3} \cdot{ }^{[5,6]}$

In recent years metal-exchanged zeolites have moved into the focus as interesting catalysts for mobile SCR applications. They are characterized by a high activity over a broad temperature range, they are nontoxic and produce little $\mathrm{N}_{2} \mathrm{O} \cdot{ }^{[7-9]}$ Iron zeolites have been on the market for quite some time and especially Fe-ZSM-5 and

\footnotetext{
${ }^{*}$ Correspondence: Dr. O. Kröcher

Paul Scherrer Institut

$\mathrm{CH}-5232$ Villigen PSI

Tel.: +41563102066

Fax: +41563102199

E-mail: oliver.kroecher@psi.ch
}

Fe-BEA are used as raw materials for the production of SCR catalysts. Metalexchanged zeolites are usually manufactured according to the following methods: i) in liquid ion exchange (W), which is the most common technology, metal salts are stirred with the zeolite base material in an aqueous slurry. ${ }^{[9,10]}$ Multiple charged ions, such as $\mathrm{Cu}^{2+}, \mathrm{Fe}^{2+}$ or $\mathrm{Fe}^{3+}$, are more difficult to stabilize inside the zeolite than single charged ions, because their charge must be compensated by several negatively charged aluminum atoms and due to their larger hydration sphere, what makes the exchange more difficult. ii) Chemical vapor ion deposition (CVD) is a process which is particularly suitable for the production of zeolites with a high exchange degree. ${ }^{[9,10]}$ A metal salt with a high vapor pressure, e.g. $\mathrm{FeCl}_{3}, \mathrm{GaCl}_{3}, \mathrm{ZnCl}_{2}$, or $\mathrm{MoCl}_{5}$, is sublimated at elevated temperature into the pores of an H-zeolite. iii) Solid-state ion exchange (SS) is particularly suitable for industrial applications. ${ }^{[9,10]}$ In this method a solid metal salt, especially metal chlorides, are homogeneously mixed with an $\mathrm{H}$-zeolite or $\mathrm{NH}_{4}$-zeolite and calcined at high temperature. ${ }^{2]}$

The basic stoichiometry of the SCR reaction (standard SCR) can be described as follows: ${ }^{[11,12]}$

$$
4 \mathrm{NH}_{3}+4 \mathrm{NO}+\mathrm{O}_{2} \rightarrow 4 \mathrm{~N}_{2}+6 \mathrm{H}_{2} \mathrm{O}
$$

With a mixture of $\mathrm{NO}$ and $\mathrm{NO}_{2}$ in the ratio 1:1 the SCR reaction proceeds according to the following stoichiometry, which is called the fast $S C R$ reaction:[11,13]

$$
4 \mathrm{NH}_{3}+2 \mathrm{NO}+2 \mathrm{NO}_{2} \rightarrow 4 \mathrm{~N}_{2}+6 \mathrm{H}_{2} \mathrm{O}
$$

A pre-condition for the SCR reaction is the preceding oxidation of part of the $\mathrm{NO}$ to adsorbed $\mathrm{NO}_{2}$ species, which are needed in the subsequent reaction sequence. ${ }^{[11,14,15]}$ Consequently the fast SCR reaction can be regarded as the actual SCR reaction on zeolites. Either $\mathrm{NO}_{2}$ must be contained in the feed gas or adsorbed $\mathrm{NO}_{2}$ like species must be formed on the catalyst at oxidation-active sites. ${ }^{[1,14]}$

In this article we review our research activities in recent years to explore the possibility for further improvements of iron-zeolite-based SCR catalysts. ${ }^{16-22]}$ In detail we were interested in the iron sites which are responsible for the SCR reaction, how hydrothermal aging affects the zeolite structure and which measures are applicable to increase the activity and improve the stability.

\section{The Role of Brønsted Acidity}

Since it is known that $\mathrm{NH}_{4}{ }^{+}$is formed, a large number of studies assume that in the SCR reaction $\mathrm{NH}_{3}$ must be bound to 
Brønsted acid sites and be activated under formation of $\mathrm{NH}_{4}^{+}$to be able to react with adsorbed $\mathrm{NO}_{x}$ species. ${ }^{[7,14,23,24]}$ However, a number of other studies on different SCR materials suggest that neither Brønsted nor Lewis acidity is a key factor with respect to NO conversion. [25-27]

In order to study the question of the participation of Brønsted acid sites in the SCR reaction, Fe-ZSM-5 samples were prepared by liquid ion exchange and chemical vapor deposition with a template-free $\mathrm{NH}_{4}$-ZSM-5 zeolite (Süd-Chemie, Si/Al $=13.5$ ). The liquid ion exchange method was optimized in such a way that the exchange was particularly mild and slow by keeping the iron concentration in the ion exchange solution almost constant, which resulted in a uniform metal ion distribution. ${ }^{[19]}$ For the investigation of the role of the Brønsted acidity in iron zeolites for the SCR reaction, catalysts with different Brønsted acidity but the same structure of the active iron sites were prepared by rendering the Brønsted sites inert by silanization. Additionally, hydrothermally aged samples were prepared, in which both the Brønsted acidity and the oxidation activity were lowered.

With $\mathrm{NH}_{3}$-TPD and DRIFTS measurements, we could demonstrate that for all exchange methods only one Brønsted acid proton was needed for the exchange of an iron ion. Fig. 1 shows that the relative concentration of Brønsted acid sites (H/ $\mathrm{Al}$ ) decreases with a slope of -1.1 in dependency of the ion exchange degree, i.e. approximately one Brønsted acid proton was required for the exchange of one iron ion. ${ }^{[18]}$

This leads to the conclusion that most iron in zeolites is bonded to ion exchange sites and that the exchanging iron species is single positively charged when using a $\mathrm{Fe}^{2+}$ salt, in contrast to some literature statements claiming that iron is generally exchanged as multiple charged species. This means that the iron ion is fixed in the ZSM-5 lattice by a single bond to aluminum over an oxygen atom and the remaining excess positive charge is compensated by $-\mathrm{OH}$ or $\mathrm{Si}-\mathrm{O}-\mathrm{Si}$ ligands, which is schematically depicted in Fig. 1.

When the SCR activity was compared with the Brønsted acidity of the samples it turned out that the two properties did not correlate. This result was supported by a detailed comparison of samples with monomeric iron sites, in which hydrothermal aging reduced the number of iron sites, Lewis acid sites as well as the Brønsted acidity by dealumination, with samples, in which only the number of Brønsted acid sites was lowered by silanization. The silanized sample, in which $96 \%$ of all Brønsted acid sites were poisoned, surprisingly showed an only slightly smaller SCR activity than the untreated sample. The slightly lower SCR activity of the silanized sample was likely caused by a steric inhibition of the $\mathrm{NH}_{3}$ diffusion in the zeolite pores by the large isopropyl groups of the silanyl compound. In contrast to this result, both hydrothermally aged samples exhibited a much lower SCR activity than the silanized sample. The lower SCR activity of the hydrothermally aged samples could be attributed to the degradation of the oxidation activity.

A relevant participation of the Brønsted acidity in the SCR reaction at low temperatures could be almost excluded on basis of the results. Brønsted acidity was indeed needed to bind the metal ions and to disperse and stabilize them in the zeolites. For the binding of $\mathrm{NH}_{3}$, however, also Lewis acid sites were sufficient. That means that it was insignificant how $\mathrm{NH}_{3}$ was bound to the catalyst surface. The catalyst acted as reservoir for $\mathrm{NH}_{3}$, which migrated to the active sites, where it reacted with NO.

\section{Estimation of the Concentration of Different Iron Species by means of a Statistic Model}

Irrespective of the iron exchange method, isolated, binuclear and oligonuclear iron species are usually found and even $\mathrm{Fe}_{2} \mathrm{O}_{3}$ particles might be formed, which

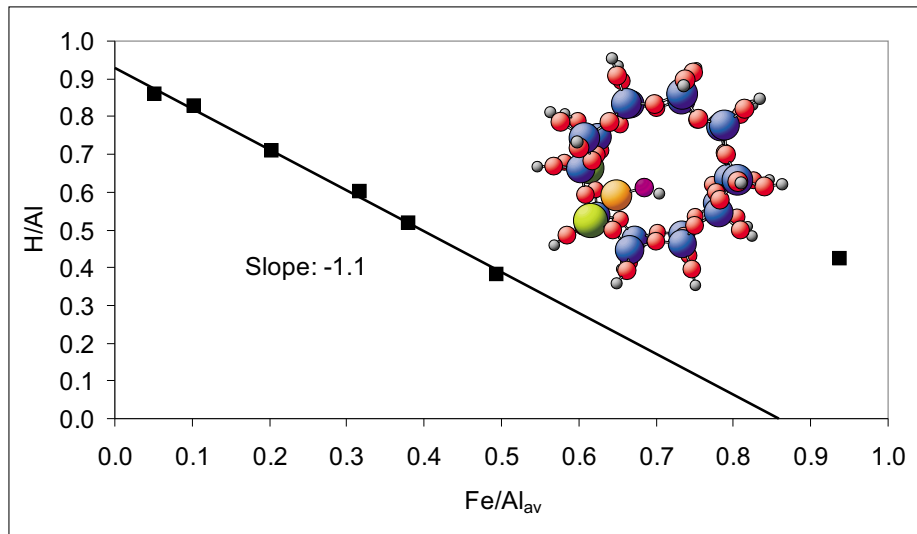

are very difficult to distinguish analytically by e.g. UV/VIS spectroscopy, EPR spectroscopy, EXAFS, XPS, $\mathrm{H}_{2}$-TPR, FTIR spectroscopy, Moessbauer spectroscopy and XRD. Therefore, the nuclearity of the oligomeric species is barely detectable, ${ }^{[28,29]}$ which aggravates or even prevents correlations between structure and function to be established.

As a consequence, we decided to use a statistic approach, with which the concentration of the isolated and clustered iron ions could be estimated. The method is based on the calculation of the statistic distribution of different iron species in dependence of the exchange degree (Fe/Al) and the $\mathrm{Si} / \mathrm{Al}$ ratio in the ZSM-5 lattice, under the assumption of an overall statistical distribution of aluminum in the zeolite framework. However, with today's analytical methods it is not possible to determine the positions of the individual aluminum atoms in the ZSM-5 lattice and, thus, to confirm a statistic distribution. ${ }^{[30,31]}$ With respect to thermodynamics, however, a statistic distribution seems to be possible in the ZSM-5 lattice, since calculations did not show substantial energetic differences when silicon atoms in different lattice positions were substituted by aluminum atoms. [32-34]

However, the preparation conditions of the zeolites, in particular the use of templates, can lead to a deviation from the statistic aluminum distribution, ${ }^{[35]}$ since the aluminum atoms, which carry a negative charge in the lattice, are preferably incorporated in the proximity of the positively charged templates. ${ }^{[36]}$ Furthermore, templates can cause an inhomogeneous aluminum distribution by the enrichment of aluminum in the boundary regions of the zeolite crystals, which is called 'zoning'. ${ }^{[37,38]}$ Therefore, we have focused the method development on samples prepared without templates.

Another condition for the application of our calculation method was that the energy of formation of isolated and oxygenbridged species was more or less equal per Fe atom, which was confirmed by DFT calculations. ${ }^{[39]}$ Furthermore, it was important that the nuclearity of the iron species depended mainly on the Fe content and not on the ion exchange method, which seemed to be true for our newly developed exchange method in this study.

With a mathematical method, which is based on such a statistic distribution, the concentration of the different iron species in a given Fe-ZSM-5 sample with $\mathrm{Si} / \mathrm{Al}=$ 14 could be estimated as a function of the exchange degree Fe/Al. On the assumption of a Poisson distribution the probability $\mathrm{P}$ could be calculated, with which $\mathrm{x}$ neighboring iron ions can be found in distance $r$ around a given iron ion. ${ }^{[40]}$ The probability 
to find an isolated iron ion and a binuclear iron species corresponded to:

$$
P_{\text {Isol. }}=\frac{N_{F e}{ }^{0} \cdot e^{-N_{F e}}}{0 !}=e^{-N_{F e}}
$$

$$
P_{\text {Dimer }}=\frac{N_{F e}^{1} \cdot e^{-N_{F e}}}{1 !} \cdot e^{-N_{F e}}
$$

The calculated probabilities for the formation of the different iron species corresponded directly to their relative concentrations. It is discernible from Fig. $2 \mathrm{a}$ that the calculated and measured concentrations of monomeric iron species agreed very well. Since with rising iron concentration the fraction of isolated iron ions decreased, the number of isolated iron ions run through a maximum, which was around $\mathrm{Fe} / \mathrm{Al} \approx 0.4$ for $\mathrm{Fe}-\mathrm{ZSM}-5$ with $\mathrm{Si}$ / $\mathrm{Al}=13.5$ (Fig. 2b). The calculated relative concentration of isolated iron ions never exceeded the limit $\mathrm{Fe}_{\text {isol }} / \mathrm{Al}=0.14$, which is in full agreement with results of Kucherov and Shelef. ${ }^{[41]}$ We compared our calculated concentrations also with results from other experimental studies in literature (data not shown) and found a good agreement.

The outstanding agreement between calculated and measured concentrations and the fact that the model was also able to describe experimental literature data from other studies shows that the presented model can predict the distribution of the

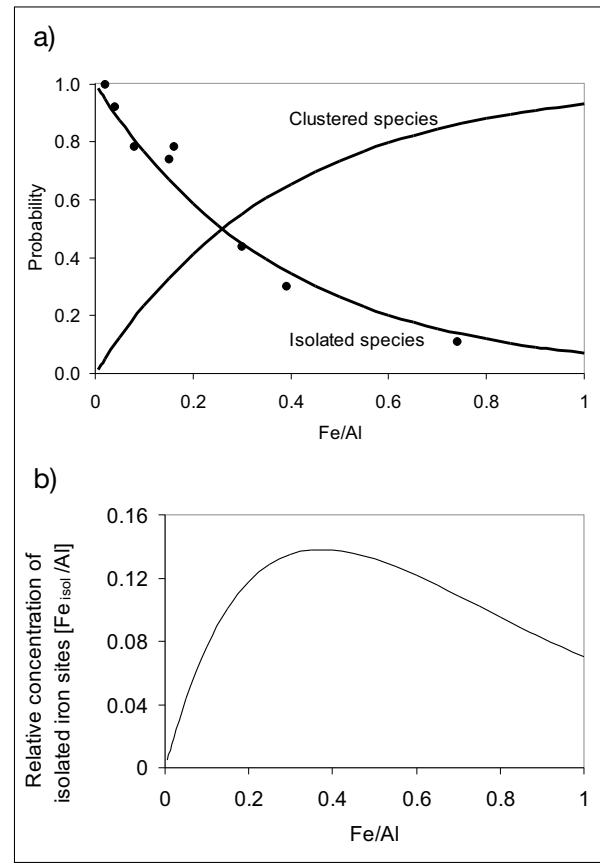

Fig. 2. a) Calculated relative concentrations of isolated iron species in Fe-ZSM-5 with $\mathrm{Si} / \mathrm{Al}=$ 13.5 as function of the exchange degree $\mathrm{Fe} /$ Al. (•) Concentration of isolated iron species measured by UV/VIS spectroscopy. b) Relative concentrations of isolated iron ions $\left[\mathrm{Fe}_{\text {isol }} / \mathrm{Al}\right]{ }^{[19]}$ different iron species. However, the use of the model is restricted to template-free produced zeolites exchanged by a suitable ion exchange method.

\section{The Nature of Active Sites}

In literature, the opinions about the nature of the active iron species in the SCR of NO strongly divert and a multiplicity of different active species are postulated, among which small $\mathrm{Fe} \mathrm{O}(\mathrm{OH})$ clusters, binuclear iron clusters ${ }^{[42-45]}$ as well as isolated $\mathrm{Fe}^{2+}$ and $\mathrm{Fe}^{3+}$ ions ${ }^{[10,44-47]}$ have been most often suggested. Regarding these species, the problem of the active iron species can actually be reduced to the question of the nuclearity of the iron.

Fig. 3 shows the measured NO conversions of H-ZSM-5 and of different FeZSM-5 zeolites with different exchange degrees. At temperatures below $350{ }^{\circ} \mathrm{C}$ the NO conversion increased with rising iron concentration, but it decreased at temperatures above $500{ }^{\circ} \mathrm{C}$ for the samples with higher iron content. Moreover, decreasing NO conversions could be observed above $500{ }^{\circ} \mathrm{C}$ with rising temperature. When the NO conversions in Fig. 3 was corrected with the conversion over H-ZSM-5 and the turnover frequencies $(\mathrm{TOF}=$ number of converted NO molecules per second per iron atom) were calculated, the activity per iron atom at low temperatures was higher in low exchanged zeolites than in highly exchanged. From this result it could be concluded that for $\mathrm{T}<300{ }^{\circ} \mathrm{C}$ the activity was probably determined by an iron species with low nuclearity or most probably by a monomeric species.

When the apparent TOF values were recalculated on basis of the estimated concentration of isolated iron ions according to the method described in section 3 , the coinciding TOF values between 200 and $300{ }^{\circ} \mathrm{C}$ indeed showed that monomeric iron species were the active ones in this temperature range (Fig. 4a). This conclusion was supported by the linear dependency of the reaction rate constants from the calculated concentration of isolated iron species at $250{ }^{\circ} \mathrm{C}$ (Fig. $4 \mathrm{~b}$ ).

We could also show that dimeric species were responsible for the activity increase in Fig. $4 \mathrm{a}$ above $\mathrm{T}=300{ }^{\circ} \mathrm{C}$ and that oligomeric species (trimers and higher) might be important for the SCR at 400 ${ }^{\circ} \mathrm{C}$ and above, since clustering of the iron species proceeded from monomeric species over dimers to oligomeric species. At temperatures above $450{ }^{\circ} \mathrm{C}$ even iron oxide nanoclusters contributed to the $\mathrm{NO}$ conversion.

The combination of optimized preparation of the Fe-ZSM-5 samples, precise activity measurements and calculation of the concentration of the active species allowed a rough estimation of the TOF values of monomeric and dimeric species in the temperature range between $200{ }^{\circ} \mathrm{C}$ and $400{ }^{\circ} \mathrm{C}$ (Table 1). The TOF values of the dimeric species could be determined from the NO conversion between 300 and 400

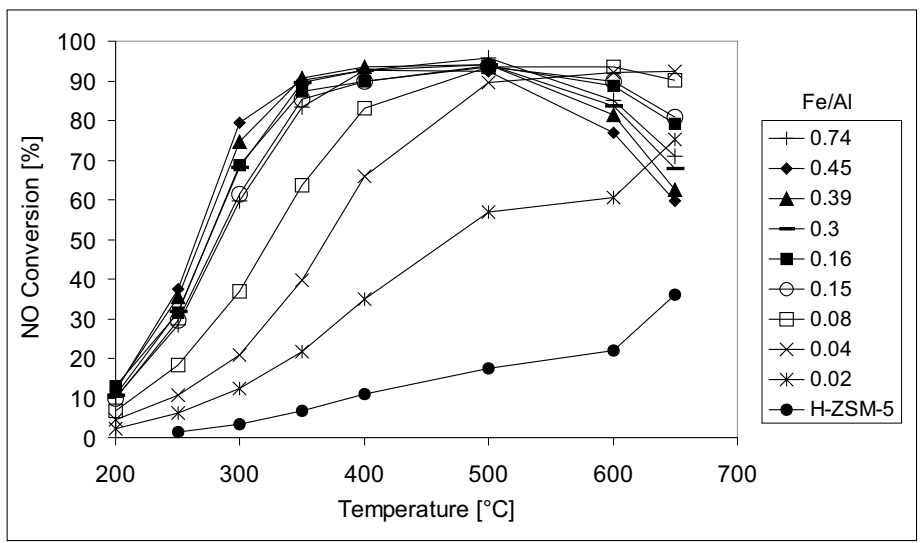

Fig. 3. Measured NO conversions over $\mathrm{H}-\mathrm{ZSM}-5$ and $\mathrm{Fe}-$ ZSM- 5 zeolites with different exchange degrees. Reaction conditions: $1000 \mathrm{ppm}$ $\mathrm{NO}$ and $\mathrm{NH}_{3}, 10 \% \mathrm{O}_{2}$, $5 \% \mathrm{H}_{2} \mathrm{O}$, balance $\mathrm{N}_{2}$. $\mathrm{GHSV}^{2}=52000 \mathrm{~h}^{-1} \cdot{ }^{2} \cdot{ }^{2}$

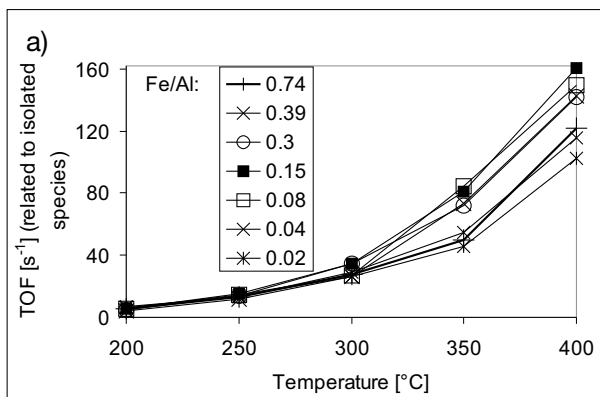

b)

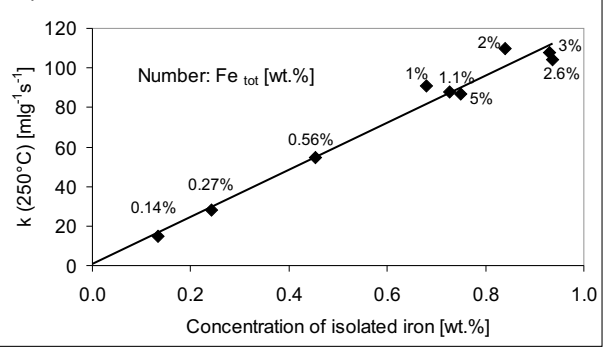

Fig. 4. a) Calculated TOF values on basis of the concentration of isolated iron species.

b) Calculated reaction rate constants in dependency of the concentration of isolated iron ions. The percentage numbers indicate the total iron concentration in the zeolite samples. ${ }^{[20]}$ 
Table 1. TOF values and apparent activation energies of different iron species in Fe-ZSM-5 in the SCR of $\mathrm{NO}$ with $\mathrm{NH}_{3} \cdot{ }^{[20]}$

\begin{tabular}{|c|c|c|c|c|}
\hline Temperature & $\begin{array}{c}\text { Isolated species } \\
\mathrm{OH}_{3+} \\
\mathrm{Fe}^{\cdots \cdots \cdot}\end{array}$ & $\mathrm{HO}_{\mathrm{Fe}^{-}}{ }^{-\mathrm{O}} \backslash_{\mathrm{Fe}}{ }^{-\mathrm{OH}}$ & $\begin{array}{l}\text { Oligomeric } \\
\text { species } \\
\mathrm{Fe}_{\mathrm{x}} \mathrm{O}_{\mathrm{y}}(\mathrm{OH})_{\mathrm{z}} \\
\mathrm{x} \geq 3\end{array}$ & $\begin{array}{c}\text { Particles } \\
\mathrm{Fe}_{2} \mathrm{O}_{3}\end{array}$ \\
\hline & $\begin{array}{c}\mathrm{E}_{\mathrm{a}, \mathrm{app}} \approx 36.3 \pm 0.2 \\
\mathrm{~kJ} / \mathrm{mol}\end{array}$ & $\mathrm{E}_{\mathrm{a}, \mathrm{app}} \approx 77 \pm 16 \mathrm{~kJ} / \mathrm{mo}$ & & \\
\hline $200{ }^{\circ} \mathrm{C}$ & $\begin{array}{c}\text { TOF }=7 \pm 0.5 \mathrm{~s}^{-1} \\
\left(200{ }^{\circ} \mathrm{C}\right)\end{array}$ & $\begin{array}{l}\mathrm{TOF} \leq 1^{\mathrm{b}} \\
\left(250^{\circ} \mathrm{C}\right)\end{array}$ & - & - \\
\hline $250{ }^{\circ} \mathrm{C}$ & $\begin{array}{c}\mathrm{TOF}=15 \pm 0.5 \mathrm{~s}^{-1} \\
\left(250{ }^{\circ} \mathrm{C}\right)\end{array}$ & $\begin{array}{c}\mathrm{TOF}=2 \pm 1 \mathrm{~s}^{-1 \mathrm{~b}} \\
\left(250^{\circ} \mathrm{C}\right)\end{array}$ & - & - \\
\hline $300{ }^{\circ} \mathrm{C}$ & $\begin{array}{c}\mathrm{TOF}=28 \pm 2 \mathrm{~s}^{-1} \\
\left(300^{\circ} \mathrm{C}\right)\end{array}$ & $\begin{array}{c}\mathrm{TOF}=8 \pm 5 \mathrm{~s}^{-1} \\
\left(300^{\circ} \mathrm{C}\right)\end{array}$ & - & - \\
\hline $350{ }^{\circ} \mathrm{C}$ & $\begin{array}{c}\mathrm{TOF}=45 \pm 2 \mathrm{~s}^{-1 \mathrm{a}} \\
\left(350^{\circ} \mathrm{C}\right)\end{array}$ & $\begin{array}{c}\text { TOF }=27 \pm 10 \mathrm{~s}^{-1} \\
\left(350^{\circ} \mathrm{C}\right)\end{array}$ & - & - \\
\hline $400^{\circ} \mathrm{C}$ & $\begin{array}{c}\mathrm{TOF}=74 \pm 4 \mathrm{~s}^{-1 \mathrm{a}} \\
\left(400^{\circ} \mathrm{C}\right)\end{array}$ & $\begin{array}{c}\mathrm{TOF}=58 \pm 13 \mathrm{~s}^{-1} \\
\left(400^{\circ} \mathrm{C}\right)\end{array}$ & Active & - \\
\hline$\geq 450^{\circ} \mathrm{C}$ & $\begin{array}{c}\text { TOF }=153 \pm 8 \mathrm{~s}^{-1 \mathrm{a}} \\
\left(500^{\circ} \mathrm{C}\right)\end{array}$ & $\begin{array}{c}\mathrm{TOF}=270 \pm 80 \mathrm{~s}^{-1 \mathrm{~b}} \\
\left(500^{\circ} \mathrm{C}\right)\end{array}$ & Active & $\begin{array}{c}\mathrm{TOF}=27 \mathrm{~s}^{-1} \\
\left(500{ }^{\circ} \mathrm{C}\right)\end{array}$ \\
\hline
\end{tabular}

aExtrapolated from an Arrhenius plot at 200,250 and $300{ }^{\circ} \mathrm{C}$;

${ }^{b}$ Extrapolated from an Arrhenius plot at 300,350 and $400{ }^{\circ} \mathrm{C}$.

${ }^{\circ} \mathrm{C}$, where both monomeric and dimeric species were active. From these NO conversions the conversions of the samples with $\mathrm{Fe} / \mathrm{Al} \leq 0.15$ were subtracted, which virtually contained only monomeric species. From these values activation energies between $45.1 \mathrm{~kJ} / \mathrm{mol}$ and $53.1 \mathrm{~kJ} / \mathrm{mol}$ could be determined with an Arrhenius plot for the samples with the different iron concentrations, which were close to the values found for Fe-ZSM-5 by Devadas et al. ${ }^{[48]}$ between $200{ }^{\circ} \mathrm{C}$ and $400{ }^{\circ} \mathrm{C}(45 \mathrm{~kJ} /$ mol) or by Huang et al. ${ }^{[23]}$ between $240{ }^{\circ} \mathrm{C}$ and $300{ }^{\circ} \mathrm{C}(54 \mathrm{~kJ} / \mathrm{mol})$, respectively. As activation energy $36.3 \pm 0.2 \mathrm{~kJ} / \mathrm{mol}$ could be determined for the monomeric species and $77 \pm 16 \mathrm{~kJ} / \mathrm{mol}$ for the dimeric species.

In summary, the results in this section demonstrate that all iron species are active regarding the SCR reaction but that their contribution to NO conversion strongly depends on the temperature. Isolated species show high NO conversions already at low temperatures, but dimeric and oligomeric species become increasingly important at higher temperatures and are finally decisive for NO conversion at the high temperature end.

With this information we were also able to explain the activity pattern observed in Fig. 3. In principle this behavior was due to the necessary oxidation of $\mathrm{NO}$ to $\mathrm{NO}_{2, \text { ads }}$ on the iron ions as the rate-determining step of the SCR reaction. At low temperature the conversion rose with increasing iron content of the zeolite, due to the increasing amount of isolated iron species, being the active species in this temperature regime.

\section{Hydrothermal Deactivation of Fe-ZSM-5 Zeolites}

Fe-ZSM-5 zeolites are interesting SCR catalysts due to their high activity, whose application at temperatures above $500{ }^{\circ} \mathrm{C}$, however, is hampered by their limited hydrothermal stability. ${ }^{[46,49]}$ The mechanism of hydrothermal deactivation is still not completely understood. It is known that during hydrothermal deactivation both the number of Brønsted acid sites and active iron sites are reduced. The loss of the active iron sites is caused by the migration of the iron ions followed by clustering under formation of inactive or only weakly active $\mathrm{FeO}_{x}$ species. ${ }^{[48-51]}$ This migration is favored by the presence of $\mathrm{H}_{2} \mathrm{O}$, which increases the mobility of the cations. ${ }^{[51,52]}$ The loss of Brønsted acidity is a consequence of dealumination by the hydrolysis of the Al-O-Si bond.[14,53,54] Although both dealumination and iron migration were extensively examined, it is unclear how both processes affect the hydrothermal deactivation and how both processes are connected. Therefore, we correlated the measured NO conversions of fresh and aged Fe-ZSM-5 samples with NMR spectroscopy, H-TPR, DRIFT spectroscopy, XANES, BET and UV/VIS spectroscopy data to draw conclusions about the processes during hydrothermal aging. ${ }^{\text {[21] }}$

The catalytic tests showed that for Fe-ZSM-5 samples with Fe/Al $\geq 0.15$ the hydrothermal stability was independent of the exchange degree. Regarding the iron species active at $\mathrm{T} \leq 400{ }^{\circ} \mathrm{C}$, aging changed the catalysts in such a way that similar iron species were formed in similar concentrations. Consequently, it could be assumed that the catalysts with $\mathrm{Fe} / \mathrm{Al} \geq 0.15$ had the same concentration of isolated iron ions after aging independently of the exchange degree. In contrast to this, the catalytic tests also revealed that zeolites with $\mathrm{Fe} /$ $\mathrm{Al} \leq 0.08$ exhibited a clearly lower stability, which was probably caused by the very small and thus very hard $\mathrm{H}^{+}$ion, reducing the electron density in the zeolite lattice more pronounced than, for example an $[\mathrm{HO}-\mathrm{Fe}-\mathrm{OH}]^{+}$ion, which is accompanied with a smaller bond strength of the iron ions to the ion exchange sites. Both DFT ${ }^{[55]}$ and quantum-mechanical computations ${ }^{[56]}$ support the theory of the influence of the protons on the zeolite charge: It could be shown that the negative charge in the zeolite lattice rises, if the negative load of the aluminum atoms is compensated by $\mathrm{Na}^{+}$ instead of $\mathrm{H}^{+}$.

Fig. 5 shows that the amount of aluminum which moved out of the lattice during aging at $650{ }^{\circ} \mathrm{C}$ in $4 \mathrm{~h}$ corresponded to the decrease of Brønsted acid groups. Only under harsher conditions $\left(650^{\circ} \mathrm{C}, 8 \mathrm{~h}\right.$ or 800 ${ }^{\circ} \mathrm{C}, 8 \mathrm{~h}$ ) was aluminum also extracted that 


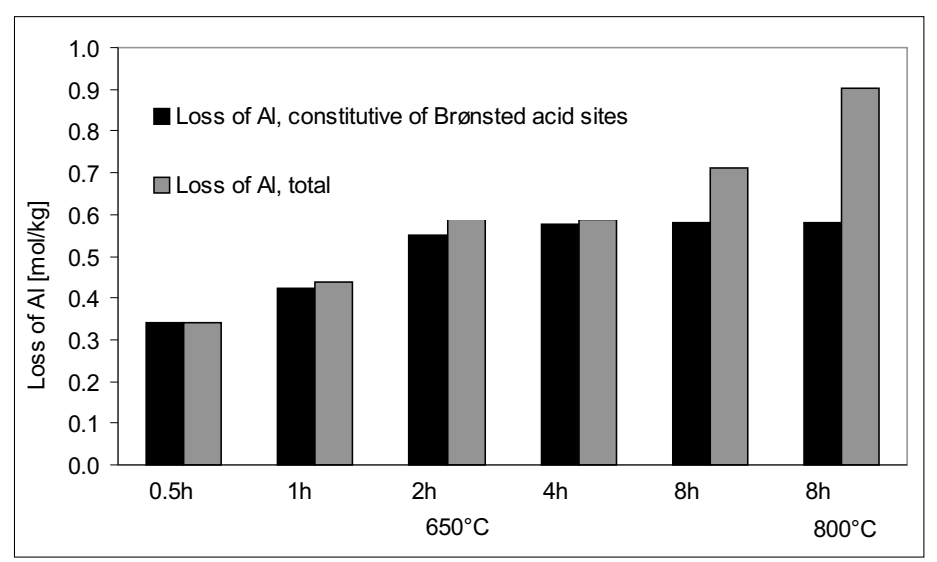

Fig. 5. Total amount of Al that moved out of the lattice (measured by ${ }^{29} \mathrm{Si} \mathrm{NMR}$ spectroscopy) and the amount of $\mathrm{Al}$ that moved out of the lattice and carried a Brønsted acid proton (measured by FTIR spectroscopy) for $\mathrm{Fe}$ ZSM-5(0.3), aged at $650^{\circ} \mathrm{C}$ for $0.5,1,2,4$ and $8 \mathrm{~h}$ and at $800{ }^{\circ} \mathrm{C}$ for $8 \mathrm{~h}$, respectively..$^{[21]}$

bound iron ions. Although the iron-binding aluminum atoms were not affected by hydrolysis at moderate ageing conditions, the migration of iron ions occurred parallel to the dealumination of the proton-binding aluminum atoms. UV/VIS measurements and the reduced fraction of redox-active iron sites during aging showed that this iron migration was the direct reason for deactivation. Moreover, EXAFS, UV/ VIS spectroscopy and TPR measurements showed that during aging clustered species were formed, which grew in size for longer ageing times.

On first view, it could be assumed that exchanged iron ions could be stabilized by Brønsted acid protons and, as a consequence, iron migration and deactivation were linked directly with dealumination. But the catalytic results did not imply such a link, since no strong stabilization or destabilization effect of Brønsted acid protons was discernible. Also the completely different rates of the loss of activity and loss of Brønsted acidity suggested that the migration of the isolated iron ions (= deactivation at $250{ }^{\circ} \mathrm{C}$ ) and the dealumination were not related to each other. A change of surface area by the dealumination could be excluded as reason for deactivation.

From the measurement results the stability of isolated and dimeric species were estimated. It was shown that the dimeric species suffered substantially more from hydrothermal deactivation than the isolated species and it could be assumed that the remaining activity was caused by the isolated iron ions. In order to examine this, the apparent activation energy was determined with an Arrhenius plot. With increasing aging decreasing activation energies were found, which were indicative of a larger fraction of isolated iron ions in the samples. The apparent activation energies of the $650^{\circ} \mathrm{C}-8 \mathrm{~h}(36.6 \mathrm{~kJ} / \mathrm{mol})$ and $800^{\circ} \mathrm{C}-8 \mathrm{~h}(34.7 \mathrm{~kJ} / \mathrm{mol})$ samples were nearly identical to the above reported apparent activation energy of $36 \mathrm{~kJ} / \mathrm{mol}$ for the isolated species in the fresh samples, which could be interpreted in such a way that the structure of the active sites in the

three samples were identical.
In summary, the results let us understand that the hydrothermal aging is dominated by three processes running in parallel (Fig. 6): The fast dealumination of the Al-OH-Si-groups, the fast deactivation of dimeric iron species and the slow migration of isolated iron ions from the ion exchange sites, followed by the hydrolysis and dealumination of Al-O-Si groups, to which the iron was bound previously. Although these processes proceed in parallel, they are not directly linked with one another. In these processes, the direct reason for the deactivation of the SCR reaction is the migration of the iron from the exchange sites. Consequently, the remaining SCR activity depends more on the bond strength of the iron ions at the exchange sites than the stability of the zeolite lattice. The amount of remaining isolated iron ions determines the residual activity.

\section{Improving the Stability and Activity of Iron-exchanged Zeolites}

Due to the limited low-temperature SCR activity of iron zeolites, measures to

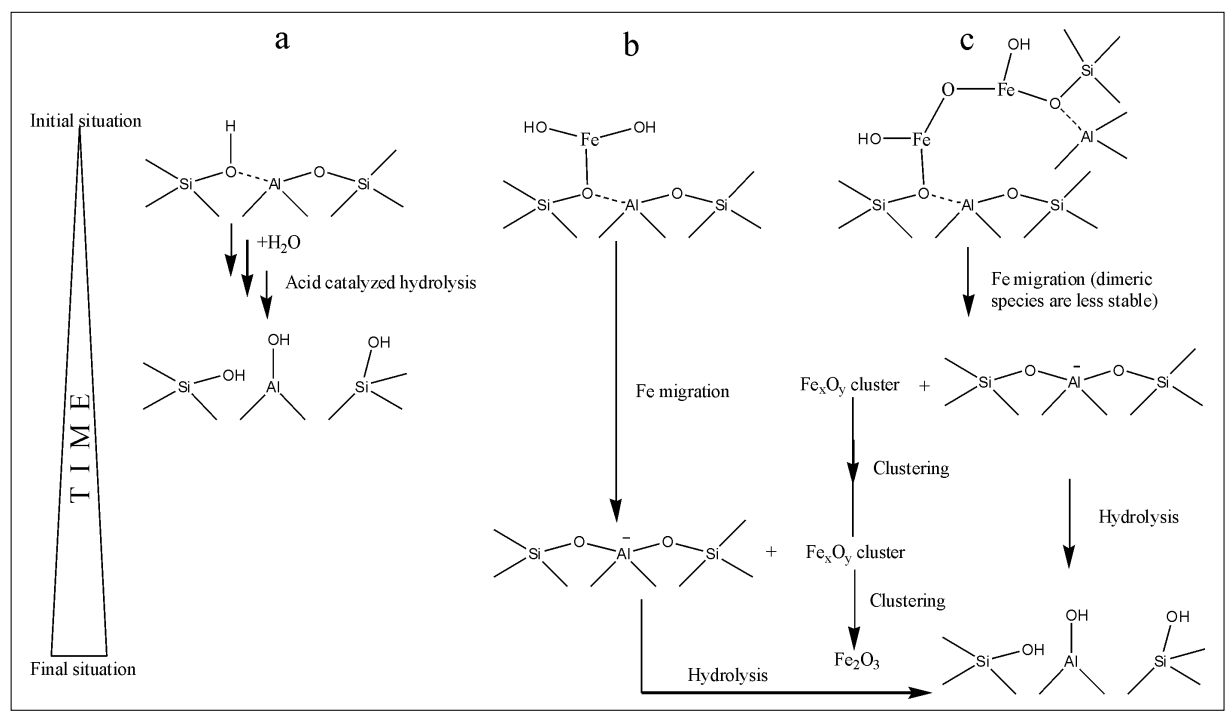

Fig. 6. Scheme of the hydrothermal aging of a) Brønsted acid sites, b) isolated iron ions and c) dimeric iron ions in Fe-ZSM-5. ${ }^{[21]}$ enhance the activity are of great interest for catalyst manufacturers. However, even more important than the activity of the fresh catalyst is its stability under hydrothermal conditions. Therefore, an important objective of this work was the stabilization of iron-exchanged zeolites against hydrothermal aging. ${ }^{[22]}$

Accordingly, the influence of different parameters on the stability and activity of metal-exchanged ZSM-5 and BEA zeolites was investigated. It was also examined if it is possible to stabilize Fe-ZSM-5, whereby the transferability of such measures to the industrial application was an important aspect.

Fe-ZSM-5 samples with the same exchange degree were prepared by liquid ion exchange (W), solid-state ion exchange (SS) and chemical vapor ion deposition (CVD). Compared to the W and SS method the CVD sample was substantially more stable, which could be explained by the presence of non-lattice aluminum and the thereby inhibited migration of iron ions. This migration of the iron ions can be also limited by using the BEA structure type instead of the ZSM-5 type. In fact, Fe-BEA proved to be significantly more stable upon hydrothermal aging at $800{ }^{\circ} \mathrm{C}$ for $8 \mathrm{~h}$ than the ZSM-5 zeolite.

The stabilization of Fe-ZSM-5 was also tried by the intended incorporation of nonlattice aluminum, but the unspecific use of aluminum nitrate did not have a positive effect. However, a clear stabilization could be achieved by the targeted reaction of the aluminum hydroxide groups in the lattice with $\mathrm{Al}(\mathrm{Me})_{3}$ followed by calcination, which reduced the migration tendency of the iron in the zeolite.

Neither the phosphatization nor the addition of lanthanum resulted in a stabilization of Fe-ZSM-5. The failure of these measures is understandable, since both 
strategies aimed at a stabilization of the Brønsted acidity, which we could exclude as crucial parameter for stability. The activation of the iron oxide species, which were formed during aging, with $\mathrm{Nb}$ or the simultaneous exchange of a secondary metal (manganese or indium) were also unsuccessful.

The use of a $\mathrm{Fe}^{3+}$ instead of $\mathrm{Fe}^{2+}$ salt was able to slightly increase the hydrothermal stability. In case of the $\mathrm{Fe}^{2+}$ salt, $\mathrm{Fe}^{2+}$ was oxidized to $\mathrm{Fe}^{3+}$ after the exchange, which resulted in a rearrangement of ligands and, thus, a destabilization of the zeolite. Although by combination of the use of a $\mathrm{Fe}^{3+}$ salt and the incorporation of non-lattice aluminum the stability of FeZSM-5 could be increased to a satisfying level, this laborious approach is unsuitable for industrial applications.

Also fluoridation did not lead to significantly more stable zeolites. In fact, the use of $\mathrm{FeF}_{2}$ for the liquid ion exchange increased the stability slightly, but its low solubility and the relatively high price of the salt hampers its application in industry.

In summary, the results confirm that it is very difficult to stabilize Fe-ZSM-5 and probably not worthwhile on an industrial scale. The application of the CVD process is also not applicable to the industrial production of iron zeolites. The zeolite structure type has to be regarded as decisive factor for the hydrothermal stability. For iron the BEA zeolite type is preferable compared to the ZSM-5 structure, but it is not clear from our results, which iron species are better stabilized.

The activity of Fe-ZSM-5 (and other SCR catalysts) can be strongly increased by adding $\mathrm{NO}_{2}$ to the feed gas. Since this is easily achieved by an oxidation catalyst upstream of the actual SCR catalyst, this is a suitable measure for diesel engine manufacturers. Since we found amazingly high SCR activities for all hydrothermally aged ZSM-5 catalysts with a feed gas containing $\mathrm{NO}_{\mathrm{x}}$ with $\mathrm{NO}: \mathrm{NO}_{2}=1: 1$, the stability problem could be overcome with this measure.

\section{Summary}

In the framework of a co-operation with the company Süd-Chemie, we systematically investigated at the Paul Scherrer Institut, to which extent Fe-ZSM-5 zeolites can be further improved for the selective catalytic reduction (SCR) of nitrogen oxides, in particular regarding the lowtemperature activity and hydrothermal stability.

The following milestones have been achieved:

- A new, mild ion exchange method was developed for incorporating iron in zeolites, which allows the preparation of well defined catalysts with very homogenously dispersed iron ions. By means of this method more precise investigations of structure-function relationships were possible.

- The problem with the quantification of the different iron species in iron zeolites could be circumvented by the development of a calculation method, which allowed the estimation of the concentrations for iron species of different nuclearity in a given Fe-ZSM-5 zeolite.

- With these tools together with the measured SCR activities it could be shown that all iron species are active in the SCR reaction, but their activities are considerably dependent on the temperature. At low temperatures isolated species are active first. Then with rising temperature increasingly clustered species become active in the reverse order of their cluster degree.

- With experiments in which the Brønsted acid protons were defunctionalized by silanization, a relevant participation of the Brønsted acid protons in the SCR reaction could be excluded. It seems to be unimportant, how $\mathrm{NH}_{3}$ is bound to the zeolite lattice.

- The SCR activity of Fe-ZSM-5 is mainly determined by its oxidation activity.

- The primary reason for the hydrothermal deactivation of Fe-ZSM-5 is the migration of iron from the exchange sites. Its stability is in principle neither affected by the exchange method nor the exchange degree.

- The structure type is the determining factor for stability of iron-exchanged zeolites and the BEA structure is better suited for iron than the ZSM-5 structure.

- The SCR activity can be significantly enhanced, especially for aged catalysts, by the addition of $\mathrm{NO}_{2}$ to the feed gas, which seems to be the easiest measure to solve the stability problem.

Received: July 11, 2012

[1] B. H. Engler, Chem. Ing. Techn. 1991, 63, 298.

[2] G. Busca, L. Lietti, G. Ramis, F. Berti, Appl. Catal. B 1998, 18, 1

[3] E. Jacob, G. Emmerling, A. Döring, U. Graf, M. Harris, B. Hupfeld, ' $\mathrm{NO}_{\mathrm{x}}$-Verminderung für Nutzfahrzeugemotoren mit HarnstoffSCR-Kompaktsystemen', in 19. Int. Wiener Motorensymposium, Ed. H.P. Lenz, VDI Reihe, Vienna, 1998, pp. 366-386.

[4] M. Devadas, G. Piazzesi, O. Kröcher, A. Wokaun, 'Mechanistic and Catalytic Investigation of Fe-ZSM-5 for Urea SCR', International Symposium on Air Pollution Abatement Catalysis, Cracow, Poland, 2005.

[5] G. Piazzesi, D. Nicosia, M. Devadas, O Krocher, M. Elsener, A. Wokaun, Catal. Lett. 2007, 115, 33.

[6] W. Held, A. Koenig, T. Richter, SAE Technical Paper Series No. 900496, 1990.

[7] R. Q. Long, R. T. Yang, J. Am. Chem. Soc. 1999, 121, 5595.
[8] R. Q. Long, R. T. Yang, J. Catal. 2002, 207, 274.

[9] J. A. Z. Pieterse, S. Booneveld, R. W. van den Brink, Appl. Catal. B 2004, 51, 215.

[10] R. Q. Long, R. T. Yang, Catal. Lett. 2001, 74, 201.

[11] M. Devadas, O. Kröcher, M. Elsener, A Wokaun, N. Soger, M. Pfeifer, Y. Demel, L. Mussmann, Appl. Catal. B 2006, 67, 187.

[12] M. Koebel, M. Elsener, M. Kleemann, Catal. Today 2000, 59, 335.

[13] M. Koebel, M. Elsener, G. Madia, SAE Technical Paper Series No. 2001-01-3625, 2001.

[14] K. Rahkamaa-Tolonen, T. Maunula, M. Lomma, M. Huuhtanen, R. L. Keiski, Catal. Today 2005, 100, 217.

[15] G. Delahay, D. Valade, A. Guzman-Vargas, B. Coq, Appl. Catal. B 2005, 55, 149.

[16] S. Brandenberger, Ph.D. Thesis, ETH Zürich No. 18867, 2010.

[17] S. Brandenberger, O. Kröcher, A. Tissler, R. Althoff, Catal. Rev. Sci. Eng. 2002, 50, 492.

[18] S. Brandenberger, O. Kröcher, A. Wokaun, A Tissler, R. Althoff, J. Catal. 2009, 268, 297.

[19] S. Brandenberger, O. Kröcher, A. Tissler, R. Althoff, Appl. Catal. A 2010, 373, 168.

[20] S. Brandenberger, O. Kröcher, A. Tissler, R. Althoff, Appl. Catal. B 2010, 95, 348.

[21] S. Brandenberger, O. Kröcher, M. Casapu, A. Tissler, R. Althoff, Appl. Catal. B 2011, 101, 649.

[22] S. Brandenberger, O. Kröcher, A. Tissler, R. Althoff, Ind. Eng. Chem. Res. 2011, 50, 4308.

[23] H. Y. Huang, R. Q. Long, R. T. Yang, Appl. Catal. A 2002, 235, 241.

[24] H. Sjovall, L. Olsson, E. Fridell, R. J. Blint, Appl. Catal. B 2006, 64, 180.

[25] M. Schwidder, M. S. Kumar, U. Bentrup, J. Perez-Ramirez, A. Bruckner, W. Grünert, Micropor. Mesopor. Mater. 2008, 111, 124.

[26] D. A. Pena, B. S. Uphade, P. G. Smirniotis, $J$. Catal. 2004, 221, 421.

[27] Z. Liu, P. J. Millington, J. E. Bailie, R. R. Rajaram, J. A. Anderson, Micropor. Mesopor. Mater. 2007, 104, 159.

[28] M. S. Kumar, Ph.D. Thesis, HumboldUniversität Berlin, 2005.

[29] G. D. Pirngruber, P. K. Roy, R. Prins, Phys. Chem. Chem. Phys. 2006, 8, 3939.

[30] J. Dedecek, D. Kaucky, B. Wichterlova, O. Gonsiorova, Phys. Chem. Chem. Phys. 2002, 4, 5406.

[31] J. A. van Bokhoven, T. L. Lee, M. Drakopoulos, C. Lamberti, S. Thiss, J. Zegenhagen, Nature Mater. 2008, 7, 551.

[32] R. Grau-Crespo, A. G. Peralta, A. R. RuizSalvador, A. Gomez, R. Lopez-Cordero, Phys. Chem. Chem. Phys. 2000, 2, 5716.

[33] K. P. Schröder, J. C. Sauer, M. Leslie, C. Richard, A. Catlow, Zeolites 1992, 12, 20.

[34] D. Nachtigallova, P. Nachtigall, M. Sierka, J. Sauer, Phys. Chem. Chem. Phys. 1999, 1, 2019.

[35] S. Sklenak, J. Dedecek, C. B. Li, B. Wichterlova, V. Gabova, M. Sierka, J. Sauer, Angew. Chem. Int. Ed. 2007, 46, 7286.

[36] D. F. Shantz, C. Fild, H. Koller, R. F. Lobo, J. Phys. Chem. B 1999, 103, 10858.

[37] U. Müller, A. Danner, P. Polanek, U. Girrbach, $\mathrm{K}$. K. Unger, in 'Innovation in zeolite materials science', Eds. P. J. Grobet, W. J. Mortier, E. F. Vansant, G. Schulz-Ekloff, Elsevier, 1988, Nieuwport, Belgium, 1987.

[38] K. J. Chao, J. Y. Chern, Zeolites 1988, 8, 82.

[39] I. Czekaj, S. Brandenberger, O. Kröcher, Micropor. Mesopor. Mater. 2012, submitted.

[40] M. J. Rice, A. K. Chakraborty, A. T. Bell, J. Catal. 1999, 186, 222.

[41] A. V. Kucherov, M. Shelef, J. Catal. 2000, 195, 106.

[42] Q. Sun, Z. X. Gao, H. Y. Chen, W. M. H. Sachtler, J. Catal. 2001, 201, 89. 
[43] A. A. Battiston, J. H. Bitter, D. C. Koningsberger, J. Catal. 2003, 218, 163.

[44] M. Schwidder, M. S. Kumar, A. Brückner, W. Grünert, Chem. Commun. 2005, 805.

[45] M. S. Kumar, M. Schwidder, W. Grünert, A Brückner, J. Catal. 2004, 227, 384.

[46] K. Krishna, M. Makkee, Catal. Today 2006, 114, 23.

[47] M. Schwidder, W. Grünert, U. Bentrup, A. Brückner, J. Catal. 2006, 239, 173

[48] M. Devadas, O. Kröcher, A. Wokaun, React. Kin. Catal. Lett. 2005, 86, 347.
[49] O. Kröcher, M. Devadas, M. Elsener, A. Wokaun, N. Soger, M. Pfeifer, Y. Demel, L. Mussmann, Appl. Catal. B 2006, 66, 208.

[50] M. Devadas, O. Kröcher, M. Elsener, A. Wokaun, G. Mitrikas, N. Söger, M. Pfeifer, Y. Demel, L. Mussmann, Catal. Today 2007, 119, 137.

[51] E. J .M. Hensen, Q. Zhu, M. Hendrix, A. R. Overweg, P. J. Kooyman, M. V. Sychev, R. A. van Santen, J. Catal. 2004, 221, 560.

[52] J. Y. Yan, G. D. Lei, W. M. H. Sachtler, H. H. Kung, J. Catal. 1996, 161, 43.
[53] T. Sano, H. Ikeya, T. Kasuno, Z. B. Wang, Y. Kawakami, K. Soga, Zeolites 1997, 19, 80.

[54] K. Ehrhardt, M. Suckow, W. Lutz, in 'Catalysis by Microporous Materials', Ed. H. K. Beyer, Elsevier, London, 1995, pp. 179

[55] D. Berthomieu, N. Jardillier, G. Delahay, B. Coq, A. Goursot, Catal. Today 2005, 110, 294.

[56] G. Delahay, E. A. Villagomez, J. M. Ducere, D. Berthomieu, A. Goursot, B. Coq, Chem. Phys. Chem. 2002, 3, 686. 